\title{
Electrocardiographic Predictors of Incident Heart Failure in Men and Women Free From Manifest Cardiovascular Disease (from the Atherosclerosis Risk in Communities [ARIC] Study)
}

\author{
Pentti M. Rautaharju, MD, PhDa, ${ }^{\star}$, Zhu-Ming Zhang, MD ${ }^{\mathrm{a}}$, Wesley K. Haisty Jr, MD ${ }^{\mathrm{b}}$, Ronald \\ J. Prineas, MB, BS, PhDa, Anna M. Kucharska-Newton, PhD, MPH ${ }^{\mathrm{C}}$, Wayne D. Rosamond, \\ $\mathrm{PhD}^{\mathrm{c}}$, and Elsayed Z. Soliman, MD, MSc, MS ${ }^{a, b}$ \\ Pentti M. Rautaharju: pentti.rautaharju@gmail.com \\ aDivision of Public Health Sciences, Epidemiological Cardiology Research Center, Wake Forest \\ School of Medicine, Winston Salem, North Carolina \\ bSection on Cardiology, Department of Medicine, Wake Forest School of Medicine, Winston \\ Salem, North Carolina \\ 'Department of Epidemiology and Community Health, University of North Carolina at Chapel Hill \\ Gillings School of Global Public Health, Chapel Hill, North Carolina
}

\begin{abstract}
The risk of incident hospitalized heart failure (HF) was evaluated for 23 electrocardiographic (ECG) variables in men and women free from cardiovascular disease. The hazard ratios with $95 \%$ confidence intervals were determined from Cox regression analysis for 13,428 participants 45 to 65 years old in the Atherosclerosis Risk in Communities (ARIC) study. New-onset HF during a 14-year follow-up period occurred in 695 men (11.9\%) and 721 women (9.5\%). Several ECG variables were significant predictors of incident $\mathrm{HF}$ when evaluated as single ECG variables. Predominant among them were spatial angles, reflecting deviations of the direction of the repolarization sequence from the normal reference direction. After controlling for collinearity among the ECG variables, the spatial angle between $T$ peak and normal $T$ reference vectors, $\Theta\left(T_{p} \mid\right.$ $\mathrm{T}_{\text {ref }}$ ), was a significant independent predictor in men (HF risk increased $31 \%$ ) and women (HF risk increased 46\%). Other independent predictors in men included epicardial repolarization time (62\% increased risk) and $\mathrm{T}$ wave peak to $\mathrm{T}$ wave end $\left(\mathrm{T}_{\mathrm{p}} \mathrm{T}_{\mathrm{e}}\right)$ interval, reflecting global dispersion of repolarization (27\% increased risk). The independent predictors in women, in addition to $\Theta\left(T_{p} \mid\right.$ $\mathrm{T}_{\text {ref }}$ ), were $\Theta(\mathrm{R} \mid \mathrm{STT})$ the spatial angle between the mean QRS and STT vectors (54\% increased risk) and QRS nondipolar voltage (46\% increased risk). In conclusion, wide $\Theta\left(T_{p} \mid T_{\text {ref }}\right)$, wide $\Theta(R \mid$ STT), and increased QRS nondipolar voltage in women and wide $\Theta\left(T_{p} \mid T_{\text {ref }}\right)$, increased epicardial repolarization time, prolonged $\mathrm{T}_{\mathrm{p}} \mathrm{T}_{\mathrm{e}}$ interval and $\mathrm{T}$ wave complexity in men were independent predictors of incident $\mathrm{HF}$, and the presence of these abnormal findings could warrant additional diagnostic evaluation for possible preventive action for HF.
\end{abstract}

Evaluation of the risk of adverse cardiac effects for QT prolongation has been the focal point of many clinical trials, particularly in the evaluation of arrhythmic events such as torsades de pointes as adverse effects of cardioactive agents. ${ }^{1}$ Of particular concern has been that $70 \%$ of torsades de pointes events occur in women. ${ }^{2}$ However, QT is known to have notable

(C) 2013 Elsevier Inc. All rights reserved.

*Corresponding author: Tel/fax: (954) 385-5622.

Disclosures: The authors have no conflicts of interest to disclose. 
limitations. ${ }^{2-5}$ Earlier investigations have found several other electrocardiographic (ECG) variables to be valuable supplements to QT in the prediction of new-onset heart failure (HF), including a wide spatial angle between the mean QRS and T vectors $[\Theta(R \mid S T T)], Q R S$ nondipolar voltage, $\mathrm{ST}$ depression in $\mathrm{V}_{1}$ and increased $\mathrm{T}$ wave $\mathrm{V}_{1}$ amplitude. ${ }^{6,7}$ The main objective of the present study was to evaluate the risk of incident hospitalized HF for a comprehensive set of repolarization-related ECG parameters derived by a recently developed repolarization mode ${ }^{8-10}$ and to evaluate gender differences in the predictors of HF.

\section{Methods}

The Atherosclerosis Risk in Communities (ARIC) study was designed as a prospective investigation of the cause and natural history of atherosclerosis, its clinical manifestations, and the community burden of coronary heart disease. The risk factors were measured and the outcomes evaluated in this population-based probability sample of adults aged 45 to 65 years at the 1987 to 1989 baseline examination; follow-up of the cohort is ongoing. The study population and definition of prevalent diseases at baseline and the outcomes have been previously described. ${ }^{11-14}$

The clinical outcomes were evaluated at the follow-up examinations through December 31, 2006. Deaths were classified as definite or possible coronary heart disease death, noncoronary heart disease death, and unclassified death. Coronary heart disease at baseline was classified as angina pectoris identified using the questionnaire from Rose et al. ${ }^{15}$ Myocardial infarction was defined by a self-reported episode requiring hospitalization for $>1$ week, myocardial infarct diagnosed by a physician, major Q waves at the baseline electrocardiogram (Minnesota Code 1.1), ${ }^{16}$ or previous coronary artery bypass grafting or coronary angioplasty. HF events were defined as a hospitalization discharge diagnosis code ("International Classification of Disease, Ninth Revision, Clinical Modification," code 428). Prevalent (baseline) HF was determined on the basis of evidence of the use of HF-related medications and classified according to the Gothenburg criteria. ${ }^{17}$ Baseline cerebrovascular disease was defined as self-reported stroke or transient ischemic attack verified by a study physician's review of the reported symptoms.

The study group of 13,428 men and women was derived from a source file of 14,126 ARIC participants, excluding those with bundle branch block or Wolf-Parkinson-White patterns (QRS duration $\geq 120 \mathrm{~ms}$ ), participants with cardiovascular disease at entry classified as coronary heart disease, stroke, or HF according to the criteria listed, and 193 participants with missing clinical data or ECG parameters from various ECG programs and special algorithms derived for the study. The mean follow-up period was 14 years.

Standardized procedures were used to record the 12-lead electrocardiograms using a MAC personal computer (Marquette Electronics, Milwaukee, Wisconsin) at each clinical center. The electrocardiograms were processed in a central ECG laboratory, initially using the Dalhousie ECG program. ${ }^{17,18}$ All electrocardiograms in the initial digital ECG file of 15,571 records were inspected visually. In addition, the ECG quality was graded using a computer algorithm. A total of 116 electrocardiograms was rejected because of poor quality or lead reversals, and electrocardiograms with a QRS duration of $\geq 120 \mathrm{~ms}$ were excluded. Occasional outliers in interval measurements by computer were corrected using an interactive computer graphics display system. All electrocardiograms were reprocessed using the GE Marquette 12-SL program (GE Marquette), and the global time points from that program were used to compute the derived ECG parameters used in the present study. However, the time point of the $\mathrm{T}$ wave end from the Dalhousie program was found to match 
more closely the visually verified $\mathrm{T}$ wave end, and the QT interval from Dalhousie program was used in the present study.

The schematic in Figure 1 illustrates the key variables of the repolarization model, defined in more explicit terms in Table 1. Because of the special importance of the QT peak interval $\left(\mathrm{QT}_{\mathrm{p}}\right)$ and $\mathrm{QT}$ end interval $\left(\mathrm{QT}_{\mathrm{e}}\right)$ for the parameters used in the repolarization model, special algorithms were used to detect the outlier measurements of $\mathrm{QT}_{\mathrm{p}}$ and $\mathrm{QT}_{\mathrm{e}}$. Genderspecific predicted values were first computed for $\mathrm{QT}_{\mathrm{e}}$ as a linear function of the RR interval derived in cardiovascular disease-free men and women. $\mathrm{QT}_{\mathrm{e}}$ values above the 99th or below the 1st percentile limit of the distribution of the difference of each interval from the predicted value were replaced by the predicted value. The rate-adjusted $\mathrm{QT}_{\mathrm{e}}$ was computed using the formula also listed in Table 1. The rate-adjusted $\mathrm{QT}_{\mathrm{p}}$ was then derived as the difference of the rate-adjusted $\mathrm{QT}_{\mathrm{e}}-\mathrm{T}$ wave peak $\left(\mathrm{T}_{\mathrm{p}}\right)-\mathrm{T}$ wave end interval. In $2 \%$ of the $\mathrm{T}_{\mathrm{p}}-\mathrm{T}$ wave end measurements, the values were $>128 \mathrm{~ms}$ and were $<50 \mathrm{~ms}$ in another $2 \%$. Outlier measurements $>128 \mathrm{~ms}$ were constrained to $128 \mathrm{~ms}$ and those $<50 \mathrm{~ms}$ to $50 \mathrm{~ms}$. Similarly, the rate-adjusted QT onset was computed using the rate-adjusted $\mathrm{QT}_{\mathrm{p}}\left(\mathrm{QT}_{\mathrm{pa}}\right)$ and $\mathrm{T}$ wave onset to $T_{p}$ as the difference between the 2 (Table 1 ).

Repolarization measurements were made using temporal reference points derived from the "global" $\mathrm{T}$ wave, the spatial $\mathrm{T}$ vector magnitude curve obtained from a transformation matrix used to derive the XYZ leads from the 8 linearly independent component leads of the 12-lead ECG signals. ${ }^{19}$ The QRS nondipolar voltage, QRS duration, and a set of 21 repolarization-related ECG variables from the repolarization model were chosen for evaluation because of their role in the generation of abnormal repolarization waveforms or because of previous data of their value as risk predictors. ${ }^{6-10}$ The QRS duration was included as the second depolarization-related parameter with the QRS nondipolar voltage, because even moderate QRS prolongation has been known to induce secondary repolarization abnormalities.

The conceptual model used to derive the repolarization parameters for the present study has been previously reported. ${ }^{8-10}$ The algorithms used to derive the epicardial repolarization time $\left(\mathrm{RT}_{\mathrm{epi}}\right)$ and other the key parameters of the repolarization model are described explicitly in Table 1. The $\mathrm{RT}_{\text {epi }}$ was obtained from the $\mathrm{QT}_{\mathrm{pa}}$, modified by the cosine of the $\mathrm{T}$ wave peak deviation angle $\left[\Theta\left(\mathrm{T}_{\mathrm{p}} \mid \mathrm{T}_{\mathrm{ref}}\right)\right]$ from the normal reference direction of repolarization $\left(\mathrm{T}_{\mathrm{ref}}\right)$ in men and women free from cardiovascular disease. Thus, $\mathrm{RT}_{\mathrm{epi}}$ was assigned the value equal to $\mathrm{QT}_{\mathrm{pa}}$ when the $\mathrm{T}_{\mathrm{p}}$ vector deviation angle was 0 (reverse repolarization sequence) and the value equal to $\mathrm{QT}_{\mathrm{pa}}$ plus left ventricular cross-mural $\mathrm{RT}$ gradient if the $T_{p}$ vector deviation angle was $180^{\circ}$ (concordant repolarization sequence). The left ventricular cross-mural RT gradient will be equal to the $T_{p} T_{x d}$ interval, where $T_{x d}$ is the time point of the minimum slope (inflexion point) at the $T$ wave downstroke. $\Theta\left(T_{p} \mid T_{\text {ref }}\right)$ is a measure of the deviation of the repolarization sequence from the normal direction of repolarization. In addition to $\Theta\left(T_{p} \mid T_{\text {ref }}\right)$ and $\Theta(R \mid S T T)$, several other spatial angles between the $\mathrm{T}$ vectors from various repolarization subintervals and other interval and amplitude variables were used in various phases of the study. Their definitions are listed in the footnotes of the corresponding tabular data. Left ventricular hypertrophy was defined by the Cornell voltage. ${ }^{20}$

Descriptive statistics were used to determine the mean values, SDs, and upper and lower 20th percentiles (quintiles) for continuous variables and numbers and percentages for categorical variables. Cox proportional hazards regression analysis was used to compute hazard ratios (HR) and 95\% confidence intervals (CIs) for the risk of HF. The ECG predictors were first evaluated as continuous variables and then stratified into quintiles. Quintiles 2 to 4 were first used as the reference group to evaluate the risk for the lowest and 
highest quintile to observe breakpoints at the high or low end of the distributions. The HRs were evaluated for increased values of the ECG parameters (quintile 5) as the test group, with quintiles 1 to 4 as the reference group. Finally, quintile 1, corresponding to decreased values, was used as the test group for $\mathrm{T}$ wave in lead $\mathrm{aVL}$ and $\mathrm{T}_{\mathrm{p}}$ in lead $\mathrm{V}$, with the remaining 4 quintiles as the reference group.

Gender interactions with HF risk for each ECG variable was evaluated, and the HRs for variables with a significant gender interaction $(\mathrm{p}<0.05)$ were listed separately for men and women; otherwise, both gender groups were combined. The HF risk data were summarized first by listing the unadjusted HRs and 95\% CIs and then for multivariate-adjusted models with an adjustment for demographic (age, race, gender, education) and clinical (smoking status, diabetes, hypertension, family history of coronary heart disease or stroke, body mass index, systolic blood pressure, total cholesterol to high-density lipoprotein cholesterol ratio, glucose, creatinine, uric acid) factors. In addition to the single ECG variable models, the independent ECG predictors for incident HF were identified. When evaluating the collinearity among the ECG variables, it was observed that rate-adjusted $\mathrm{QT}_{\mathrm{e}}$ and rateadjusted QT onset correlated highly with $\mathrm{QT}_{\mathrm{pa}}$, which is functionally closely related to $\mathrm{RT}_{\text {epi }}$. From these 4 variables, it was decided to retain $\mathrm{RT}_{\text {epi }}$ because of its central role in the repolarization model. The remaining set of ECG variables with low correlations $(r<0.5)$ was chosen to evaluate the independent ECG predictors of incident HF. These variables were entered simultaneously into Cox regression model, first without additional adjustment and then after adjustment for demographic and clinical factors. Statistical analyses were performed using Statistical Analysis Systems, version 9.1.3 (SAS Institute, Cary, North Carolina) and Microsoft Excel 2007 version 5.0 (Microsoft, Redmond, Washington).

\section{Results}

The age range of the study population was 45 to 65 years (mean age 54; Table 2). The study population was predominantly white $(73 \%)$. Some notable gender differences of clinical interest were present in the ECG parameters. The rate-adjusted $\mathrm{QT}_{\mathrm{e}}$ was $10 \mathrm{~ms}$ shorter and the rate-adjusted $\mathrm{QT}_{\mathrm{p}} 18 \mathrm{~ms}$ shorter in the men than in the women. The $\Theta(\mathrm{R} \mid \mathrm{STT})$ was $10^{\circ}$ wider in the men than in the women. Notable among the other gender differences were the lower $\mathrm{T}$ onset vector magnitude and $\mathrm{T}_{\mathrm{p}}$ vector magnitude in women than in men and greater $\mathrm{T}$ wave onset $/ \mathrm{T}_{\mathrm{p}}$ vector magnitude ratio in the men than in the women.

New-onset HF occurred in 695 men (11.9\%) and 721 women (9.5\%). Summary results for the ECG predictors of incident HF are presented in Table 3 for multivariate-adjusted single ECG variable models such that the risk of incident HF was evaluated separately for each of the 23 ECG variables. A significant gender interaction with incident HF was found for 13 ECG variables, which have been listed separately for men and women in Table 3. For most of these 13 variables, the HRs were slightly stronger for the men than the women, and for 4 of the variables, the HR was significant for men only. The highest increased risk of incident HF in men, 1.76-fold, was observed for the spatial angle $\Theta\left(T_{\text {init }} \mid T_{\text {term }}\right)$ and 1.71-fold increased risk for T-wave aVR amplitude. Of the remaining $10 \mathrm{ECG}$ variables with no significant gender interaction, the HRs were significant for 5, with the highest level of increased risk of incident HF for 2 of the spatial angles, 1.63-fold for $\Theta(R \mid S T T)$ and 1.59fold for $\Theta\left(T_{p} \mid T_{\text {ref }}\right)$.

Independent ECG predictors for incident HF were identified after considering collinearity among the ECG variables, as described in the "Methods" section. The correlation matrix in Table 4 lists the ECG variables with low correlation $(r<0.5)$ chosen to evaluate independent predictors of incident HF. The risk of incident HF for these 8 variables was evaluated by entering them simultaneously into the multiple ECG variable models, and each variable was 
thus adjusted to the other ECG variables without any additional adjustment. Four ECG variables for men and three for women were significant independent predictors of incident HF (Table 5). $\Theta\left(\mathrm{T}_{\mathrm{p}} \mid \mathrm{T}_{\text {ref }}\right)$ was a significant independent predictor in men (HF risk increased $31 \%$ ) and in women (HF risk increased $46 \%$ ). The other independent predictors were the epicardial RT (62\% increased risk) and $\mathrm{T}_{\mathrm{p}}-\mathrm{T}$ wave end interval (27\% increased risk) in men and the QRS nondipolar voltage (46\% increased risk) in women.

\section{Discussion}

The most salient results from the present investigation can be summarized as follows. First, most of the ECG variables evaluated were predictors of hospitalized HF as significant as single ECG variables with adjustment for demographic and clinical variable. Second, after controlling for collinearity among the ECG variables, the significant independent predictors of hospitalized incident HF in women were $\Theta(R \mid S T T)$, with $54 \%$ increased risk, $\Theta\left(T_{p} \mid T_{\text {ref }}\right)$, with $46 \%$ increased risk, and QRS nondipolar voltage with $46 \%$ increased risk. Third, in men, the significant independent predictors were $\Theta\left(\mathrm{T}_{\mathrm{p}} \mid \mathrm{T}_{\text {ref }}\right)$, with $31 \%$ increased risk, $\mathrm{RT}_{\text {epi }}$, with $62 \%$ increased risk, $\mathrm{T}_{\mathrm{p}}-\mathrm{T}$ wave end interval, with $62 \%$ increased risk, and $\mathrm{T}$ wave complexity, with $32 \%$ increased risk.

It should be noted that this set of independent predictors of incident HF is not unique, because many ECG variables were highly correlated. In particular, if $\mathrm{QT}_{\mathrm{p}}$ or $\mathrm{QT}_{\mathrm{e}}$ had been chosen for evaluation of independent predictors, instead of $\mathrm{RT}_{\mathrm{epi}}$, the HRs would have been close to those observed for $\mathrm{RT}_{\text {epi }}$. Similarly, some STT variables such as the T- wave aVR amplitude and $\mathrm{ST}$ onset amplitude in $\mathrm{V}_{6}$ would likely be significant predictors of incident $H F$ if chosen for evaluation instead of $\Theta\left(T_{p} \mid T_{r e f}\right)$ or $\Theta(R \mid S T T)$ because of the high level of correlation between them.

Concerning the validity of the repolarization model, electrophysiologic evidence, ${ }^{21-23}$ and electrocardiographic potential theory applied to the generation of $\mathrm{T}$ waves support the concept that with normal direction of the repolarization sequence, $\mathrm{RT}_{\text {epi }}$ coincides with the time point of $T_{p}$. The timing of the endocardial RT was less clear. The repolarization model assumes that the inflexion point at global $\mathrm{T}$ wave downstroke occurs when the largest number of left ventricular myocytes leaves phase 3 of their action potential within the same increment of RT. It is conceivable that this occurs when most endocardial myocytes have reached the end of phase 3 of their repolarization. The repolarization model uses the $T_{p} T_{x d}$ interval (where $\mathrm{T}_{\mathrm{xd}}$ is the time point of the minimum slope [inflexion point] at the $\mathrm{T}$ wave downstroke) and $\mathrm{RT}_{\text {epi }}$ to derive a tentative estimate for a representative value for endocardial RT.

$\Theta\left(T_{p} \mid T_{\text {ref }}\right)$ is a measure of deviation of the direction of the repolarization sequence from normal reference direction during initial repolarization phases dominated by regional crossmural repolarization of the left ventricular lateral wall. Figure 2 shows a progressive decrease in $T$ wave $V_{5}$ amplitude with $\Theta\left(T_{p} \mid T_{\text {ref }}\right)$ widening from its median value of $17^{\circ}$ to $42^{\circ}$ at the 95 th percentile of the $\Theta\left(T_{p} \mid T_{\text {ref }}\right)$ distribution. The $T$ wave at lead $V_{5}$ becomes flat and slightly negative at $\Theta\left(T_{p} \mid T_{\text {ref }}\right)$, widening to $65^{\circ}$, the $98 \%$ normal limit. Although not shown, a parallel change occurs in $\mathrm{T}$ wave of lead aVR, which becomes progressively less negative and turns positive at abnormal widening of $\Theta\left(T_{p} \mid T_{\text {ref }}\right)$. The trends in the men were closely similar to those in the women. $\Theta\left(T_{p} \mid T_{\text {ref }}\right)$ and other spatial angles reflecting deviation of the repolarization sequence from normal reference direction might have utility in the evaluation of regional contributions to the prolongation of the overall QT interval and global RT, particularly in various abnormal clinical conditions and as an abnormal response to cardioactive agents. 
Coronary heart disease, valvular heart disease, and hypertensive heart disease are clinically known to be the primary determinants of HF. In our study population, the prevalence of ECG left ventricular hypertrophy was low (1.5\% in men and 3.9\% in women), just as was the prevalence of Q wave myocardial infarction (3.0\% in men and $1.4 \%$ in women). Thus, in these cardiovascular disease-free men and women, the ECG predictors of incident HF might be early manifestations of otherwise undetected coronary heart disease or hypertensive heart disease.

In an earlier ARIC study with 9 years of follow-up, the QRS nondipolar voltage was an independent ECG predictor of risk of new-onset HF only in women, just as it was in the present ARIC study with 14 years of follow-up. In postmenopausal women in the Women's Health Initiative study, the independent predictors of incident HF were wide $\Theta(R \mid S T T)$, STsegment depression in $\mathrm{V}_{1}$, increased $\mathrm{T}$ wave $\mathrm{V}_{1}$ amplitude, QT prolongation, and increased heart rate variability. ${ }^{7} \mathrm{QRS}$ nondipolar voltage was the only significant depolarizationrelated predictor in women in that study. Previous studies have postulated microvascular disease and fragmentation of ventricular conduction as a possible mechanism for QRS nondipolar voltage as a predictor of incident HF. However, in the Women's Ischemia Syndrome Study (WISE), a wide QRS/T angle, QRS duration, and prolonged QT interval were independent predictors of incident fatal and nonfatal coronary heart disease events, but the QRS nondipolar voltage was not. ${ }^{24}$ The question of the mechanism for increased risk of incident HF for QRS nondipolar voltage in women remains open.

Incident HF events in the study group were identified by hospitalization and evidence of HF as the discharge diagnosis, without, however, performing centralized adjudication. The study population consisted of men and women free of clinically manifest cardiovascular disease; however, no clinical data with evaluation of cardiac function were available for the present study.

\section{Acknowledgments}

The Atherosclerosis Risk in Communities Study was performed as a collaborative study. We thank the staff and participants of the ARIC study for their important contributions.

This work was supported by contracts HHSN268201100005C, HHSN268201100006C, HHSN268201100007C, HHSN268201100008C, HHSN268201100009C, HHSN268201100010C, HHSN268201100011C, and HHSN268201100012C from the National Heart, Lung, and Blood Institute (Bethesda, Maryland).

\section{References}

1. Zhang Y, Post WS, Blasco-Colmenares E, Dalal D, Tomaselli GF, Guallar E. Electrocardiographic QT interval and mortality: a metaanalysis. Epidemiology. 2011; 22:660-670. [PubMed: 21709561]

2. Makkar RR, Fromm BS, Steinman RT, Meissner MD, Lehmann MH. Female gender as a risk factor for torsades de pointes associated with cardiovascular drugs. JAMA. 1993; 270:2590-2597. [PubMed: 8230644]

3. Roden DM. Drug-induced prolongation of the QT interval. N Engl J Med. 2004; 350:1013-1022. [PubMed: 14999113]

4. Shah R, Hondeghem LM. Refining detection of drug-induced proarrhythmia: QT interval and TRIaD. Heart Rhythm. 2005; 2:758-772. [PubMed: 15992736]

5. Huikuri HV, Castellanos A, Myerburg RJ. SCD due to cardiac arrhythmias. N Engl J Med. 2001; 345:1473-1482. [PubMed: 11794197]

6. Rautaharju PM, Prineas RJ, Wood J, Zhang ZM, Crow R, Heiss G. Electrocardiographic predictors of new-onset heart failure in men and in women free of coronary heart disease (from the Atherosclerosis in Communities [ARIC] Study). Am J Cardiol. 2007; 100:1437-1441. [PubMed: 17950804] 
7. Rautaharju PM, Kooperberg C, Larson JC, LaCroix A. Electrocardiographic predictors of incident congestive heart failure and all-cause mortality in postmenopausal women. The Women's Health Initiative Circulation. 2006; 113:481-489.

8. Rautaharju PM, Zhou SH, Gregg RE, Startt-Selvester RH. Electrocardiographic estimates of action potential durations and transmural repolarization time gradients in healthy subjects and in acute coronary syndrome patients - profound differences by sex and by presence vs absence of diagnostic ST elevation. J Electrocardiol. 2011; 44:309-319. [PubMed: 21511065]

9. Rautaharju PM, Zhou SH, Gregg RE, Startt-Selvester RH. Electrocardiographic estimates of regional action potential durations and repolarization time subintervals reveal ischemia-induced abnormalities in acute coronary syndrome not evident from global QT. J Electrocardiol. 2011; 44:718-724. [PubMed: 22018486]

10. Rautaharju PM, Zhou SH, Gregg RE, Startt-Selvester RH. Heart rate, gender differences, and presence versus absence of diagnostic ST elevation as determinants of spatial QRS|T angle widening in acute coronary syndrome. Am J Cardiol. 2011; 107:744-750.

11. The ARIC Investigators. The Atherosclerosis in Communities (ARIC) study: design and objectives. Am J Epidemiol. 1989; 129:687-702. [PubMed: 2646917]

12. White AD, Folsom AR, Chambless LE, Sharret AR, Yang K, Conwill D, Higgins M, Eillismd OD, Tyroler HA. Community surveillance of coronary heart disease in the Atherosclerosis Risk in Communities (ARIC) Study: methods and initial two years' experience. J Clin Epidemiol. 1996; 49:223-233. [PubMed: 8606324]

13. Vitelli LL, Crow RS, Shahar E, Hutchinson RG, Rautaharju PM, Folsom AR. Electrocardiographic findings in a healthy biracial population: the ARIC Study. Am J Cardiol. 1998; 81:453-459. [PubMed: 9485136]

14. Loehr LR, Rosamond WD, Chang PP, Folsom AR, Chambless LE. Heart failure incidence and survival (from the Atherosclerosis Risk in Communities study). Am J Cardiol. 2008; 101:10161022. [PubMed: 18359324]

15. Rose, GA.; Blackburn, H.; Gillum, RF.; Prineas, RJ. Cardiovascular Survey Methods. Geneva, Switzerland: World Health Organization; 1982.

16. Blackburn H, Keys A, Simonson E, Rautaharju P, Punsar S. The electrocardiogram in population studies: a classification system. Circulation. 1960; 21:1160-1175. [PubMed: 13849070]

17. Wolf, HK.; MacInnis, PJ.; Stock, S.; Helppi, RK.; Rautaharju, PM. The Dalhousie program: a comprehensive analysis program for rest and exercise electrocardiograms. In: Zywiets, C.; Schneider, B., editors. Computer Application on ECG and VCG Analysis. Amsterdam: North Holland Publishing; 1973. p. 231-240.

18. Rautaharju PM, MacInnis PJ, Warren JW, Wolf HK, Rykers PM, Calhoun HP. Methodology of ECG interpretation in the Dalhousie Program: NOVACODE ECG classification procedures for clinical trials and population health surveys. Methods Inf Med. 1990; 29:362-374. [PubMed: 2233384]

19. Horáĉek BM, Warren JW, Field DQ, Feldman CL. Statistical and deterministic approaches to designing transformations of electrocardiographic leads. J Electrocardiol. 2002; 35(suppl):41-52. [PubMed: 12539098]

20. Casale PN, Devereux RB, Alonso DR, Campo E, Kligfied P. Improved sex-specific criteria for left ventricular hypertrophy for clinical and computer interpretation of electrocardiograms: validation with autopsy findings. Circulation. 1987; 75:565-572. [PubMed: 2949887]

21. Yan GX, Antzelevitch C. Cellular basis for the normal T wave and the electrocardiographic manifestations of the long-QT syndrome. Circulation. 1998; 98:1928-1936. [PubMed: 9799215]

22. Zhu TG, Patel C, Martin S, Quan X, Wu Y, Burke JF, Chernick M, Kowey PR, Yan GX. Ventricular transmural repolarization sequence: its relationship with ventricular relaxation and role in ventricular diastolic function. Eur Heart J. 2009; 30:372-380. [PubMed: 19147608]

23. Xia Y, Liang Y, Kongstad O, Liao Q, Holm M, Olsson B, Yan S. In vivo validation of the coincidence of the peak and end of the $\mathrm{T}$ wave with full repolarization of the epicardium and endocardium. Heart Rhythm. 2005; 2:162-169. [PubMed: 15851290] 
24. Triola B, Olson MB, Reis SE, Rautaharju P, Merz CN, Kelsey CF, Shaw LJ, Sharaf BL, Sopko G, Saba S. Electrocardiographic predictors of cardiovascular outcome in women: the NHLBIsponsored WISE study. J Am Coll Cardiol. 2005; 45:51-56. [PubMed: 15992635] 


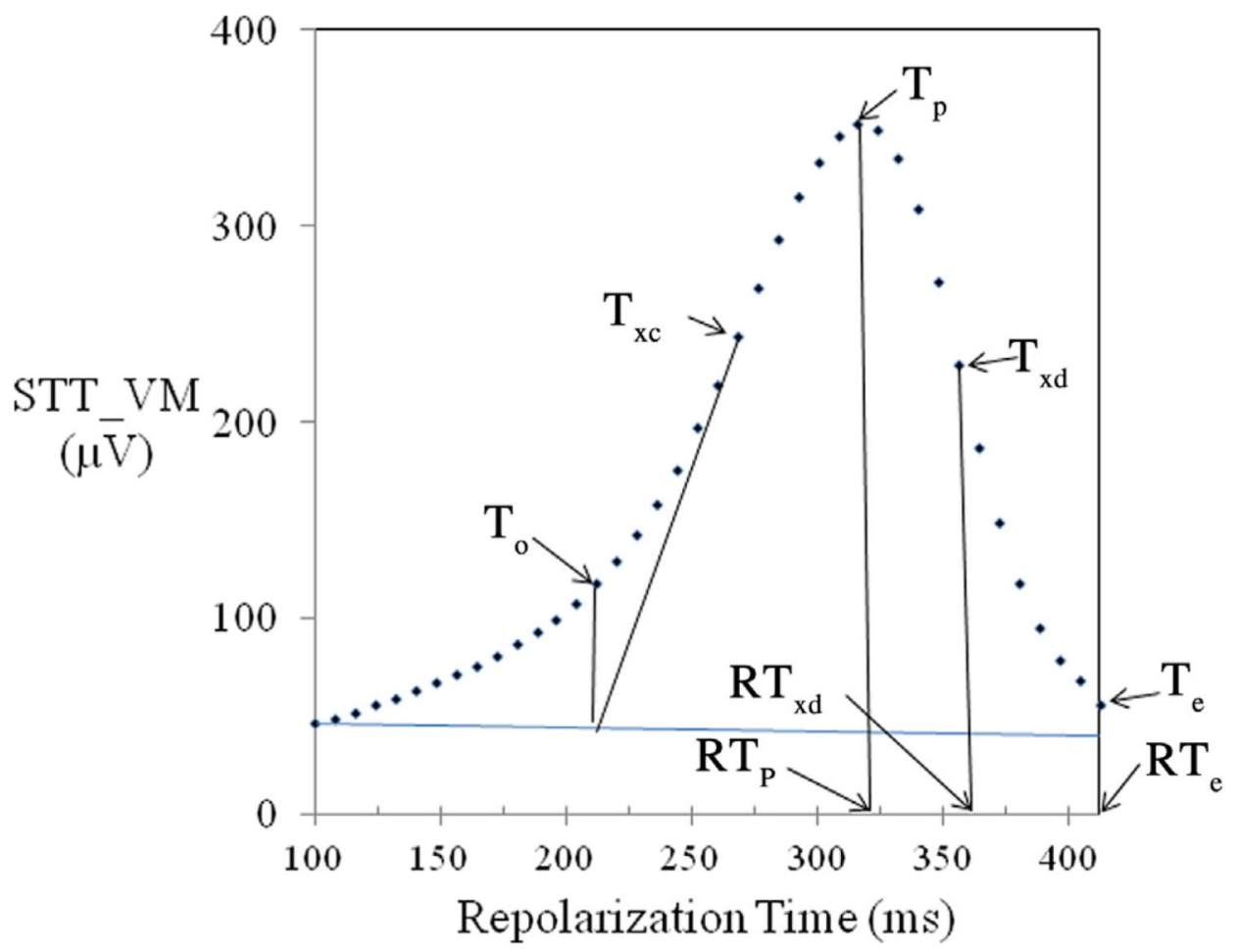

Figure 1.

A schematic illustrating key repolarization model's variables defined explicitly in Table 1. In normal repolarization sequence, $\mathrm{RT}_{\mathrm{p}}$ represents the $\mathrm{RT}_{\text {epi }}$. The $\mathrm{T}_{\mathrm{p}} \mathrm{T}_{\mathrm{e}}$ interval is a measure of global temporal RT gradient or global RT dispersion, and the $\mathrm{T}_{\mathrm{p}} \mathrm{T}_{\mathrm{xd}}$ interval is the local left ventricular free wall cross-mural RT gradient $\left(\mathrm{XMRT}_{\text {grad }}\right)$. A line extrapolated backward to the intersection of the horizontal line from the end of QRS identified time point of $\mathrm{T}_{\mathrm{o}} \cdot \mathrm{T}_{\mathrm{e}}=$ $\mathrm{T}$ wave end; $\mathrm{T}_{\mathrm{O}}=\mathrm{T}$ wave onset; $\mathrm{T}_{\mathrm{xc}}=$ inflexion point (maximum slope) at $\mathrm{T}$ wave upstroke; $\mathrm{T}_{\mathrm{xd}}=$ inflexion point (minimum slope) at $\mathrm{T}$ wave downstroke. STT vector magnitude curve is shown at 40 sample points along RT from $\mathrm{QRS}$ end to $\mathrm{T}_{\mathrm{e}}$. Arrows at $\mathrm{RT}_{\mathrm{p}}, \mathrm{RT}_{\mathrm{xd}}$, and $\mathrm{RT}_{\text {end }}$ indicate $\mathrm{RT}$ at point of $\mathrm{T}_{\mathrm{p}}, \mathrm{T}_{\mathrm{xd}}$, and $\mathrm{T}_{\mathrm{e}}$, respectively. 


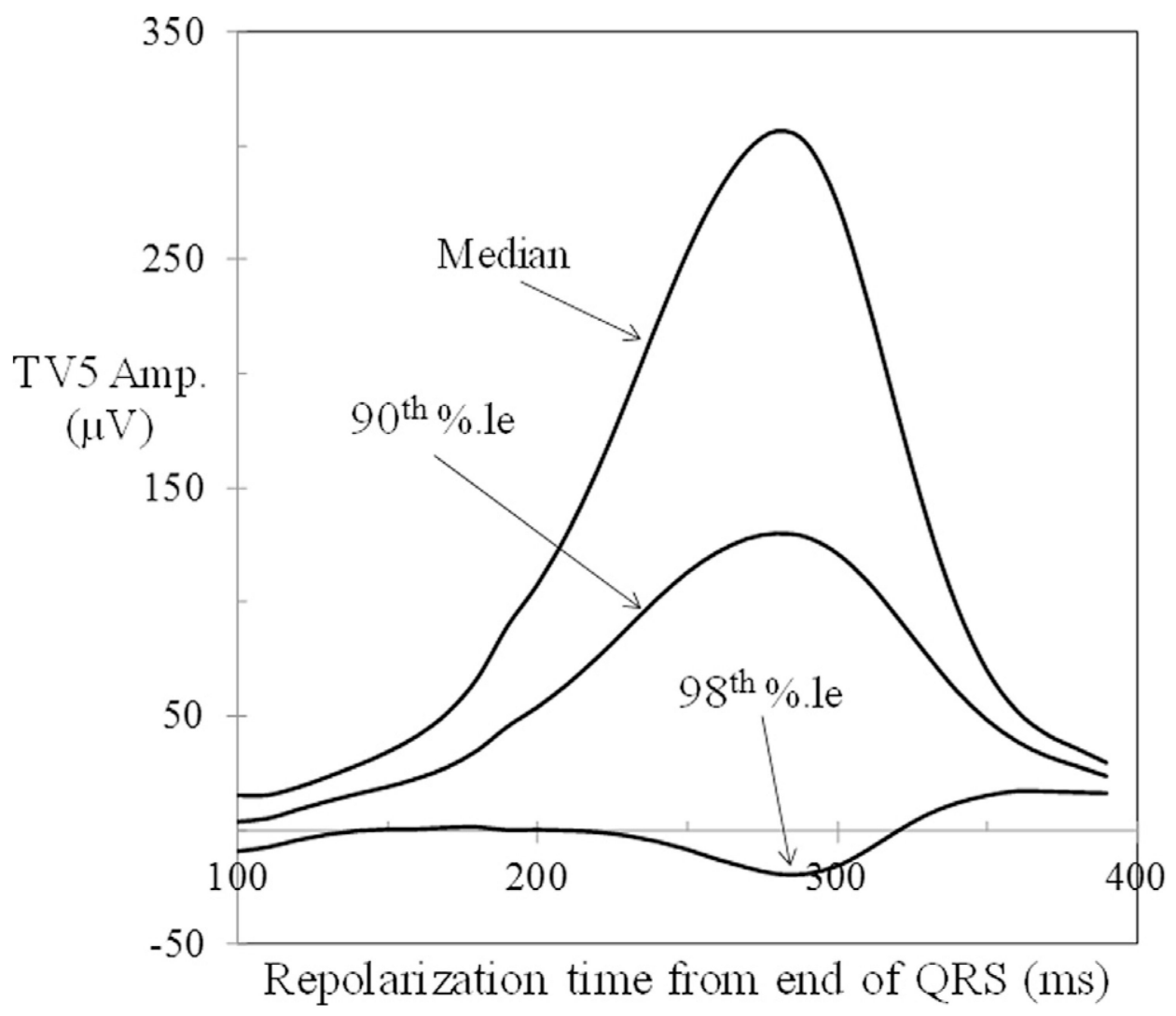

Figure 2.

$\mathrm{TV}_{5}$ waveforms in women free of cardiovascular disease with widening of the spatial angle between $T_{p}$ and normal $T$ reference vectors, $\Theta\left(T_{p} \mid T_{\text {ref }}\right)$. A progressive decrease occurred in $\mathrm{TV}_{5}$ amplitude with $\Theta\left(\mathrm{T}_{\mathrm{p}} \mid \mathrm{T}_{\text {ref }}\right)$ widening from the median $17^{\circ}$ to $42^{\circ}$ at the 95 th percentile. $\mathrm{TV}_{5}$ becomes flat and slightly negative at $\Theta\left(\mathrm{T}_{\mathrm{p}} \mid \mathrm{T}_{\text {ref }}\right)$, widening to $65^{\circ}$, the $98 \%$ normal limit. As a parallel change (not shown), aVR amplitudes became progressively less negative and turned positive at abnormal widening of $\Theta\left(\mathrm{T}_{\mathrm{p}} \mid \mathrm{T}_{\mathrm{ref}}\right)$. The trends in men were closely similar to those in women. 
Table 1

Definitions of electrocardiographic variables used in the repolarization model

\begin{tabular}{|c|c|c|}
\hline Acronym & Description & Excel Algorithm \\
\hline \multirow[t]{2}{*}{ Pred. $\mathrm{QT}_{\mathrm{e}}$} & Predicted QT end interval (ms) & Pred. $\mathrm{QT}_{\mathrm{e}}=183 \times \mathrm{RR}+224$ in men \\
\hline & & Pred. $\mathrm{QT}_{\mathrm{e}}=188 \times \mathrm{RR}+228$ in women \\
\hline \multirow[t]{2}{*}{$\mathrm{QT}_{\mathrm{ea}}^{*}$} & Rate-adjusted $\mathrm{QT}_{\mathrm{e}}$ interval (ms) & $\mathrm{QT}_{\mathrm{ea}}=\mathrm{QT}_{\mathrm{e}}+183 \times(1-\mathrm{RR})$ for men \\
\hline & & $\mathrm{QT}_{\mathrm{ea}}=\mathrm{QT}_{\mathrm{e}}+186 \times(1-\mathrm{RR})$ for women \\
\hline $\mathrm{QT}_{\mathrm{pa}}$ & Rate-adjusted QT peak interval (ms) & $\mathrm{QT}_{\mathrm{pa}}=\mathrm{QT}_{\mathrm{ea}}-\mathrm{T}_{\mathrm{p}} \mathrm{T}_{\mathrm{e}}$, where $\mathrm{T}_{\mathrm{p}} \mathrm{T}_{\mathrm{e}}$ is the interval from $\mathrm{T}$ wave peak to $\mathrm{T}$ wave end \\
\hline $\mathrm{QT}_{\mathrm{oa}}$ & Rate-adjusted QT onset interval (ms) & $\mathrm{QT}_{\mathrm{oa}}=\mathrm{QT}_{\mathrm{pa}}-\mathrm{T}_{\mathrm{o}} \mathrm{T}_{\mathrm{p}}$, where $\mathrm{T}_{\mathrm{o}} \mathrm{T}_{\mathrm{p}}$ is the interval from $\mathrm{T}$ wave onset to $\mathrm{T}$ wave peak \\
\hline$\Theta\left(\mathrm{T}_{\mathrm{p}} \mid \mathrm{T}_{\mathrm{ref}}\right)$ & $\begin{array}{l}\mathrm{T}_{\mathrm{p}} \text { vector deviation angle from normal } \\
\text { reference direction }\left({ }^{\circ}\right)\end{array}$ & $\begin{array}{l}\Theta\left(\mathrm{T}_{\mathrm{p}} \mid \mathrm{T}_{\text {ref }}\right)=57.3 \times \operatorname{archcosine}\left(\mathrm{T}_{\text {ref }} \mathrm{x} \times \mathrm{T}_{\mathrm{p}} \mathrm{x}+\mathrm{T}_{\text {ref }} \mathrm{y} \times \mathrm{T}_{\mathrm{p}} \mathrm{y}+\mathrm{T}_{\text {ref }} \mathrm{z} \times \mathrm{T}_{\mathrm{p}} \mathrm{z}\right) /\left(\mathrm{T}_{\text {ref }} \mathrm{V} \times\right. \\
\left.\mathrm{T}_{\mathrm{p}} \mathrm{V}\right)^{\dagger}\end{array}$ \\
\hline $\mathrm{TpT}_{\mathrm{xd}}$ & $\begin{array}{l}\text { Left ventricular cross-mural repolarization } \\
\text { time gradient }(\mathrm{ms})\end{array}$ & $\begin{array}{l}T_{p} T_{x d}=\text { interval from } T_{p} \text { to } T_{x d} \text {, where } T x d \text { is the inflection point at global } T \text { wave } \\
\text { downstroke }\end{array}$ \\
\hline $\mathrm{RT}_{\text {epi }}$ & Epicardial repolarization time (ms) & $\mathrm{RT}_{\mathrm{epi}}=\mathrm{QT}_{\mathrm{pa}}-\left(\operatorname{Cos} \Theta\left(\mathrm{T}_{\mathrm{p}} \mid \mathrm{T}_{\mathrm{ref}}\right)-1\right) \times \mathrm{T}_{\mathrm{p}} \mathrm{T}_{\mathrm{xd}} / 2$ \\
\hline $\mathrm{RT}_{\mathrm{xd}}$ & $\begin{array}{l}\text { Left ventricular repolarization time at time } \\
\text { point Txd (ms) }\end{array}$ & $\mathrm{RT}_{\mathrm{xd}}=\mathrm{QT}_{\mathrm{pa}}+\left(\operatorname{Cos} \Theta\left(\mathrm{T}_{\text {init }} \mid \mathrm{T}_{\text {ref }}\right)+1\right) \times \mathrm{T}_{\mathrm{p}} \mathrm{T}_{\mathrm{xd}} / 2$ \\
\hline
\end{tabular}

R-square 0.81 for men, 0.77 for women in regression of $\mathrm{QT}_{\mathrm{e}}$ on RR interval.

${ }^{t_{\text {In }}} \Theta\left(\mathrm{T}_{\mathrm{p}} \mid \mathrm{T}_{\mathrm{ref}}\right)$ algorithm, $\mathrm{T}_{\mathrm{ref}} \mathrm{x}, \mathrm{T}_{\mathrm{ref}} \mathrm{y}, \mathrm{T}_{\mathrm{ref}} \mathrm{z}, \mathrm{T}_{\mathrm{p}} \mathrm{x}, \mathrm{T}_{\mathrm{p}} \mathrm{y}$, and $\mathrm{T}_{\mathrm{p}} \mathrm{z}$ are the $\mathrm{x}, \mathrm{y}$, and $\mathrm{z}$ components of $\mathrm{T}_{\mathrm{ref}}$ and $\mathrm{T}_{\mathrm{p}}$ vectors; $\mathrm{T}_{\mathrm{ref}} \mathrm{V}$ is the vector magnitude of $\mathrm{T}_{\text {ref }}$ Vector $(=1)$; and $\mathrm{T}_{\mathrm{p}} \mathrm{V}$ is the vector magnitude of $\mathrm{T}_{\mathrm{p}}$ vector; $\mathrm{T}_{\text {ref }}$ is the normal $\mathrm{T}$ reference vector in men and women free of cardiovascular disease with unit Vector xyz components $(0.66,0.48,-0.67)$. Spatial direction of repolarization is diametrically opposite to $\mathrm{T}_{\text {ref }}$ vector. 
Table 2

Characteristics of study population for key demographic, clinical, and electrocardiographic (ECG) variables stratified by gender

\begin{tabular}{|c|c|c|}
\hline Variable & Men $(n=5,842)$ & Women $(\mathrm{n}=7,596)$ \\
\hline \multicolumn{3}{|l|}{ Demographic/clinical } \\
\hline Age (yrs) & $54.2 \pm 5.8$ & $53.6 \pm 5.7^{*}$ \\
\hline Body mass index $\left(\mathrm{kg} / \mathrm{m}^{2}\right)$ & $27 \pm 4.1$ & $28 \pm 6.0$ \\
\hline White & $4,563(77 \%)$ & $5,450(71 \%)^{*}$ \\
\hline Current smokers & $1,623(27 \%)$ & $1,877(25 \%)^{*}$ \\
\hline Systolic blood pressure (mm Hg) & $122 \pm 17.5$ & $120 \pm 19.2^{*}$ \\
\hline Hypertension & $1,837(31 \%)$ & $2,442(32 \%)$ \\
\hline Diabetes mellitus & $621(11 \%)$ & $785(10 \%)$ \\
\hline Q wave myocardial infarction by Minnesota Code criteria & $179(3.0 \%)$ & $107(1.4 \%)^{*}$ \\
\hline LVH by Cornell Voltage & $91(1.5 \%)$ & $297(3.9 \%)^{*}$ \\
\hline LVH and strain & $9(0.2 \%)$ & $34(0.4 \%)$ \\
\hline \multicolumn{3}{|l|}{ ECG parameters } \\
\hline Heart rate & $65 \pm 10.2$ & $67 \pm 10.0^{*}$ \\
\hline PR interval (ms) & $166 \pm 25.5$ & $161 \pm 25.4^{*}$ \\
\hline QRS duration $(\mathrm{ms})$ & $95 \pm 9.1$ & $87 \pm 8.3^{*}$ \\
\hline $\operatorname{RNDPV}(\mu \mathrm{V})$ & $54 \pm 22.6$ & $43 \pm 17.4^{*}$ \\
\hline $\mathrm{QT}_{\mathrm{ea}}(\mathrm{ms})$ & $408 \pm 12.9$ & $415 \pm 14.1^{*}$ \\
\hline $\mathrm{QT}_{\mathrm{pa}}(\mathrm{ms})$ & $316 \pm 18.7$ & $334 \pm 18.2^{*}$ \\
\hline $\mathrm{QT}_{\mathrm{oa}}(\mathrm{ms})$ & $226 \pm 18.9$ & $244 \pm 19.3^{*}$ \\
\hline $\mathrm{RT}_{\mathrm{epi}}(\mathrm{ms})$ & $318 \pm 19.3$ & $336 \pm 18.7^{*}$ \\
\hline $\mathrm{RT}_{\text {endo }}(\mathrm{ms})$ & $351 \pm 18.6$ & $367 \pm 18.2^{*}$ \\
\hline $\mathrm{T}_{\mathrm{p}} \mathrm{T}_{\mathrm{xd}}(\mathrm{ms})$ & $37 \pm 10.2$ & $35 \pm 11.4^{*}$ \\
\hline $\mathrm{T}_{\mathrm{p}} \mathrm{T}_{\mathrm{e}}(\mathrm{ms})$ & $91 \pm 14.9$ & $81 \pm 14.98^{*}$ \\
\hline$\Theta(\mathrm{R} \mid \mathrm{STT})\left(^{\circ}\right)$ & $58 \pm 26.8$ & $48 \pm 24.5^{*}$ \\
\hline$\Theta\left(R_{p} \mid T_{p}\right)\left(^{\circ}\right)$ & $51 \pm 30.5$ & $39 \pm 19.4^{*}$ \\
\hline$\Theta\left(\mathrm{T}_{\mathrm{p}} \mid \mathrm{T}_{\mathrm{ref}}\right)\left(^{\circ}\right)$ & $21 \pm 16.3$ & $26 \pm 18.4^{*}$ \\
\hline$\Theta\left(\mathrm{T}_{\text {init }} \mid \mathrm{T}_{\text {term }}\right)\left({ }^{\circ}\right)$ & $18 \pm 11.5$ & $16 \pm 11.0^{*}$ \\
\hline $\mathrm{T}$ wave complexity & $0.34 \pm 0.16$ & $0.36 \pm 0.18^{*}$ \\
\hline $\operatorname{TaVR}(\mu \mathrm{V})$ & $-219 \pm 96.9$ & $-201 \pm 86.9^{*}$ \\
\hline $\operatorname{TaVL}(\mu \mathrm{V})$ & $94 \pm 95.5$ & $75 \pm 80.3^{*}$ \\
\hline $\mathrm{TV}_{1}(\mu \mathrm{V})$ & $-133 \pm 145.6$ & $-12 \pm 119.8^{*}$ \\
\hline $\mathrm{ST}_{\mathrm{o}} \mathrm{V}(\mu \mathrm{V})$ & $54 \pm 27.9$ & $36 \pm 19.8^{*}$ \\
\hline $\mathrm{T}_{\mathrm{o}} \mathrm{V}(\mu \mathrm{V})$ & $148 \pm 56.7$ & $104 \pm 41.1^{*}$ \\
\hline
\end{tabular}




\begin{tabular}{ccc}
\hline Variable & Men $(\mathbf{n}=\mathbf{5 , 8 4 2})$ & Women $(\mathbf{n}=\mathbf{7 , 5 9 6})$ \\
\hline $\mathrm{T}_{\mathrm{p}} \mathrm{V}(\mu \mathrm{V})$ & $390 \pm 141.3$ & $315 \pm 122.5^{*}$ \\
$\mathrm{VT}_{\mathrm{o}} / \mathrm{VT}_{\mathrm{p}}(\mu \mathrm{V})$ & $0.39 \pm 0.09$ & $0.36 \pm 0.11^{*}$ \\
\hline
\end{tabular}

$\Theta(R \mid S T T)$ and $\Theta\left(R_{p} \mid T_{p}\right)=$ spatial angle $(\Theta)$ between mean $Q R S$ and STT and between $R_{p}$ and $T_{p}$ vectors, respectively; $\Theta\left(T_{\text {init }} \mid T_{\text {term }}\right)=$ spatial angle between the initial $T$ vectors from quintiles $1-3$ and the terminal $T$ vectors from quintiles 4 and $5 ; \Theta\left(T_{p} \mid T_{\text {ref }}\right)=$ spatial angle between $T_{p}$ vector and $\mathrm{T}$ reference $\left(\mathrm{T}_{\mathrm{ref}}\right)$ vector; $\mathrm{LVH}=$ left ventricular hypertrophy; $\mathrm{MI}=$ myocardial infarction; $\mathrm{QT}_{\mathrm{oa}}, \mathrm{QT}_{\mathrm{ea}}$, and $\mathrm{QT}$ pa $=\mathrm{QT}$ onset and $\mathrm{QT}$ end intervals, respectively, rate-adjusted with formulas listed in Table 1; RNDPV = QRS non-dipolar voltage from singular value decomposition (square root of pooled variance of components 4 to 8); $\mathrm{RT}_{\text {epi }}$ and $\mathrm{RT}_{\mathrm{endo}}=$ epicardial and endocardial repolarization time, respectively (see "Methods" section); $\mathrm{T}_{\mathrm{O}} \mathrm{V} / \mathrm{T}_{\mathrm{p}} \mathrm{V}=$ ratio of $\mathrm{T}_{\mathrm{O}}$ and $\mathrm{T}_{\mathrm{p}}$ spatial vector magnitudes; $\mathrm{TpT}_{\mathrm{e}}=$ interval from $\mathrm{QT} \mathrm{p}$ to end of global $\mathrm{T}$ wave, representing global repolarization time gradient; $\mathrm{T}_{\mathrm{p}} \mathrm{T}_{\mathrm{xd}}=$ interval from $\mathrm{T}_{\mathrm{p}}$ to $\mathrm{T}_{\mathrm{Xd}}\left(\mathrm{T}_{\mathrm{p}} \mathrm{T}_{\mathrm{xd}}\right.$ represents left ventricular cross-mural repolarization time gradient); $\mathrm{T}$ wave complexity $=$ ratio of the second to the first principal component from singular value decomposition of the $\mathrm{T}$ wave; $\mathrm{T}_{\mathrm{Xd}}=$ inflection point at $\mathrm{T}$ wave downstroke; $\mathrm{V}$ in $\mathrm{ST}_{\mathrm{O}} \mathrm{V}, \mathrm{T}_{\mathrm{o}} \mathrm{V}$, and $\mathrm{T}_{\mathrm{p}} \mathrm{V}=$ spatial magnitudes of $\mathrm{ST}_{\mathrm{O}}, \mathrm{T}_{\mathrm{O}}$, and $\mathrm{T}_{\mathrm{p}}$ vectors.

*

$\mathrm{p}<0.001$.

${ }^{\dagger} \mathrm{p}<0.05$, z-test for proportions and $t$ test for gender differences. 
Table 3

Hazard ratios (HRs) with $95 \%$ confidence intervals (CIs) for electrocardiographic (ECG) predictors of incident heart failure (HF) from multivariate-adjusted risk model in men and women

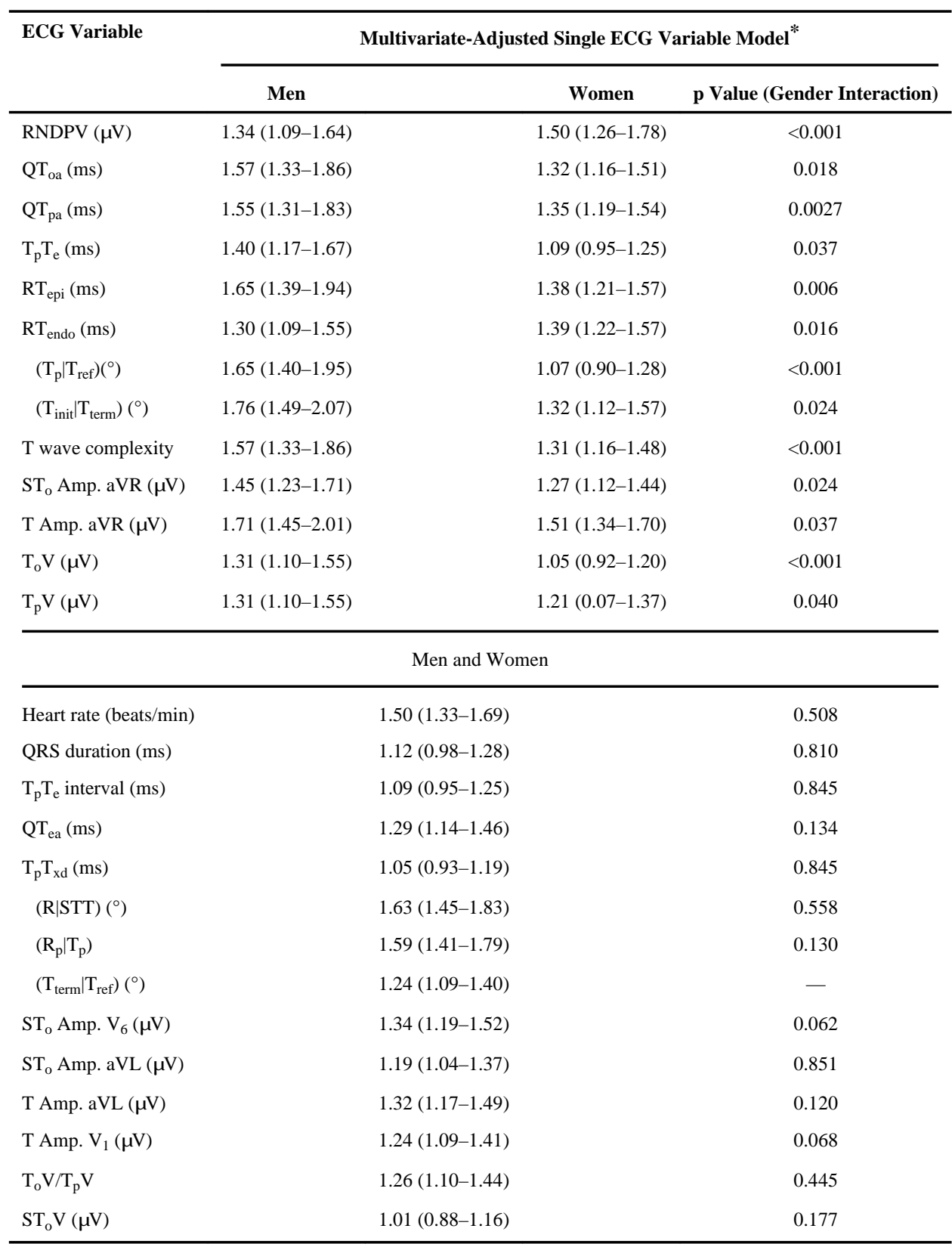

HRs evaluated for quintile 5 (quintile 1 for $\mathrm{QT}_{\mathrm{Oa}}$ and $\mathrm{T}_{\mathrm{p}} \mathrm{V}$ ) as the test group, with the remaining 4 quintiles as the reference group. HRs for ECG variables with significant gender interaction for HF risk are listed separately for men and women, otherwise the gender groups were combined.

$\Theta(R \mid S T T)=$ spatial angle between the mean QRS and STT vectors; $\Theta\left(R_{p} \mid T_{p}\right)=$ spatial angle between peak QRS and T vectors $\left(R_{p}\right.$ and T respectively); $\Theta\left(\mathrm{T}_{\text {init }} \mid \mathrm{T}_{\text {term }}\right)=$ spatial angle between initial and terminal $\mathrm{T}$ vectors from $\mathrm{T}$ wave quintiles $1-3$ and 4 and 5 , respectively; $\Theta\left(\mathrm{T}_{\mathrm{p}} \mid\right.$ $\left.T_{\text {ref }}\right)=$ spatial angle between $T_{p}$ vector and $T$ reference $\left(T_{\text {ref }}\right)$ vector; $\Theta\left(T_{\text {term }} \mid T_{\text {ref }}\right)=$ spatial angle between mean terminal $T$ vector from $T$ wave 
quintiles 4 and 5 and $\mathrm{T}_{\text {ref vector; }} \mathrm{QT}_{\mathrm{Oa}}$ and $\mathrm{QT}_{\mathrm{pa}}$ and $\mathrm{QT}_{\mathrm{ea}}=$ rate-adjusted QT onset, QT peak, and QT end intervals (formulas listed in Table 1); $\mathrm{RNDPV}=\mathrm{QRS}$ nondipolar voltage from singular value decomposition (square root of pooled variance of components 4-8); $\mathrm{RT}_{\text {epi }}$ and $\mathrm{RT}_{\mathrm{endo}}=$ epicardial and endocardial repolarization time, respectively (see Figure 1 and "Methods" section); STo Amp. = ST onset amplitude at end of QRS (the J-point); $\mathrm{T}_{\mathrm{O}} \mathrm{V} / \mathrm{T}_{\mathrm{p}} \mathrm{V}=$ ratio of $\mathrm{T}_{\mathrm{O}}$ and $\mathrm{T}_{\mathrm{p}}$ vector magnitudes; $\mathrm{TpT}_{\mathrm{e}}=$ interval from the peak to the end of the global $\mathrm{T}$ wave, considered as global RT gradient; $\mathrm{T}_{\mathrm{p}} \mathrm{T}_{\mathrm{Xd}}=$ interval from $\mathrm{T}_{\mathrm{p}}$ to inflection point at $\mathrm{T}$ wave downstroke $\left(\mathrm{T}_{\mathrm{Xd}}\right)$ considered as cross-mural repolarization time gradient (XMRTgrad); $\mathrm{T}$ wave complexity = ratio of second to first principal component from singular value decomposition of $\mathrm{T}$ wave; $\mathrm{V}$ in $\mathrm{ST}_{\mathrm{O}} \mathrm{V}, \mathrm{T}_{\mathrm{O}} \mathrm{V}$, and $\mathrm{T}_{\mathrm{p}} \mathrm{V}=$ vector magnitude of $\mathrm{ST}_{\mathrm{O}}, \mathrm{T}_{\mathrm{O}}$, and $\mathrm{T}_{\mathrm{p}}$ vectors, respectively.

Adjusted for age, race, education level, smoking status, alcohol status, asthma, cancer, diabetes, hypertension, family history of coronary heart disease and stroke, body mass index, systolic and diastolic blood pressure, high-density lipoprotein, low-density lipoprotein, triglycerides, white blood cells, glucose, creatinine, and uric acid.

Statistically significant. 


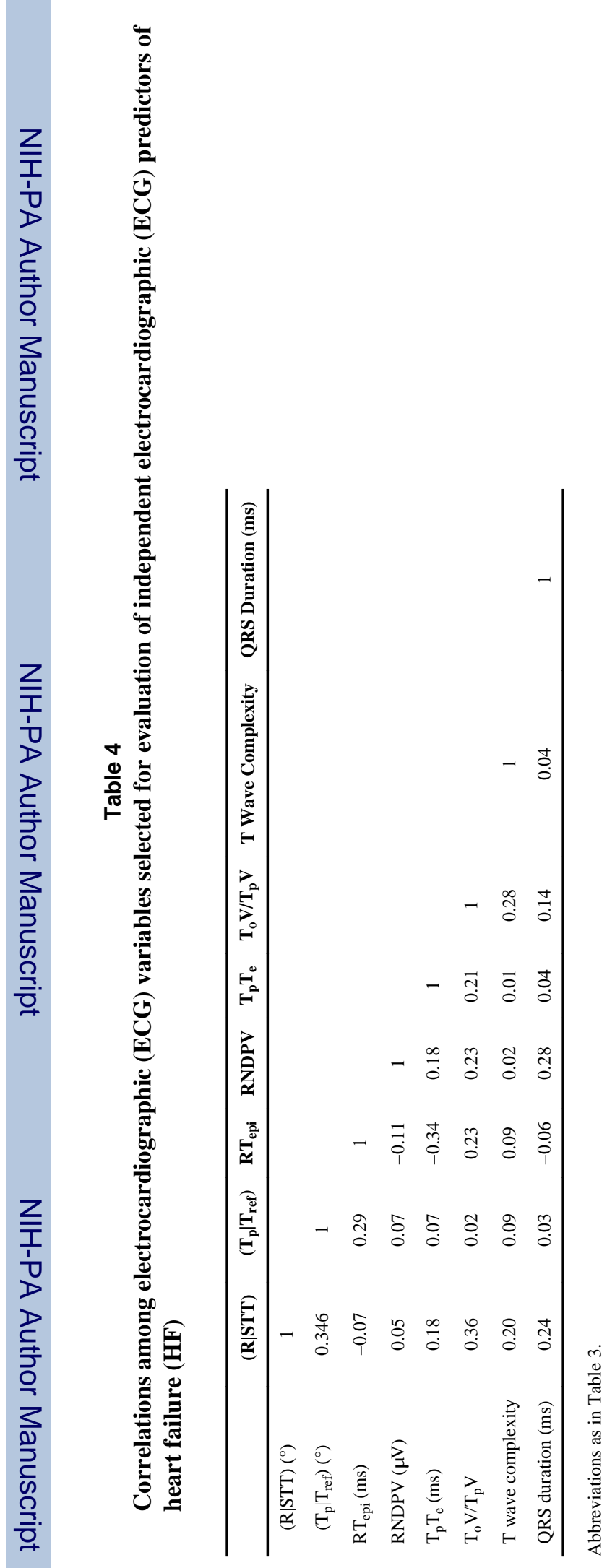

Am J Cardiol. Author manuscript; available in PMC 2014 September 15. 
Table 5

Hazard ratios (HRs) and $95 \%$ confidence intervals (CIs) for independent predictors* of incident heart failure (HF) by gender and cardiovascular disease status at baseline

\begin{tabular}{lcccc}
\hline CVD-Free Men & & \multicolumn{2}{c}{ CVD-Free Women } \\
\cline { 1 - 2 } ECG Predictors With Test Group Threshold & HR $(\mathbf{9 5 \%}$ CI $)$ & & ECG Predictors With Test Group Threshold & HR (95\% CI) \\
\hline $\mathrm{RT}_{\mathrm{epi}}>329 \mathrm{~ms}$ & $1.62(1.34-1.97)^{\dagger}$ & & $\mathrm{RNDPV}>54 \mu \mathrm{V}$ & $1.46(1.24-1.73)^{\dagger}$ \\
$\mathrm{T}_{\mathrm{p}} \mathrm{T}_{\mathrm{e}}>110 \mathrm{~ms}$ & $1.27(1.06-1.54)^{\dagger}$ & & $\Theta(\mathrm{R} \mid \mathrm{STT})>64^{\circ}$ & $1.54(1.29-1.85)^{\dagger}$ \\
$\Theta\left(\mathrm{T}_{\mathrm{p}} \mid \mathrm{T}_{\text {ref }}\right)>28^{\circ}$ & $1.31(1.07-1.61)^{\xi}$ & & $\Theta\left(\mathrm{T}_{\mathrm{p}} \mid \mathrm{T}_{\mathrm{ref}}\right)>28^{\circ}$ & $1.46(1.21-1.76)^{\dagger}$ \\
$\mathrm{T}$ complexity & $1.32(1.10-1.58)^{\xi}$ & & \\
\hline
\end{tabular}

$\Theta(R \mid S T T)=$ spatial angle between the mean QRS and STT vectors; $\Theta\left(T_{p} \mid T_{\text {ref }}\right)=$ spatial angle between $T$ peak vector and reference $T$ vector $\left(T_{\text {ref }}\right)$ with $\mathrm{x}, \mathrm{y}, \mathrm{z}$ components $(0.686,0.528,-0.501)$ (direction of repolarization is diametrically opposite to Tref vector); CVD = cardiovascular disease; $\mathrm{RNDPV}=$ non-dipolar $\mathrm{QRS}$ voltage; $\mathrm{RT}_{\text {epi }}=$ epicardial repolarization time; $\mathrm{TpTe}=\mathrm{T}$ peak- $\mathrm{T}$ end interval $\left(\right.$ global $\mathrm{RT}_{\text {grad }}$ ) $\mathrm{T}$ wave complexity = ratio of second to first principal component of $\mathrm{T}$ wave from singular value decomposition.

Independent predictors were obtained by entering the predictors significant on univariate single ECG parameter models simultaneously into Cox regression model and adjusting each variable to other significant ECG predictors. HRs were evaluated for quintile 5. with quintiles 1-4 as the reference group.

$t_{\mathrm{p}}<0.001$.

$*_{\mathrm{p}}<0.05$.

$\xi_{\mathrm{p}<0.01 \text { for HR. }}$ 